\title{
Narrow canal and laminectomy women cases taken under spinal anesthesia
}

\begin{abstract}
Among the superiorities of regional anesthesia over general anesthesia are; Complications such as a decrease in functional residual capacity in the lungs, and infections such as infection are less likely to develop after general anesthesia. Decreased blood loss in the intra operative period; in the post operative period, Preferred reasons are decreased nauseavomiting frequency and analgesic requirement, decreased vein thrombus and pulmonary embolism. Necessary permission obtained from legal representat. Spinal anesthesia was applied to patients 50 females, who underwent spinal surgery (20 spinal stenosis, 64 laminectomy) between November 2012 and September 2013 at the State Hospital. The age distribution of the patients was the smallest 23 and the largest 77.33 of the patients; $12.5 \mathrm{mg}$ heavy marcain and $25 \mathrm{mcg}$ fentanyl were administered intrathecally to the patients with a $25 \mathrm{G}$ pencil point spinal needle. Patients were given $1 \mathrm{mg}$ midazolam for sedation.
\end{abstract}

Volume 8 Issue 4 - 2020

\author{
Hayriye Alp \\ GETAT(CAM), Necmettin Erbakan University Meram Medical \\ Faculty Hospital, Turkey
}

Correspondence: Hayriye Alp, GETAT(CAM), Necmettin Erbakan University Meram Medical Faculty Hospital, Konya, Turkey, Email hayriyebalp@yahoo.com

Received: July 06, 2020 | Published: December 24, 2020

Keywords: women, spinal anesthesioloy, laminectomy, surgery

\section{Introduction}

Epidural and spinal anesthesia applications are becoming more common in lumbar discectomy and laminectomy surgery. ${ }^{1-6}$ Among the superiorities of regional anesthesia over general anesthesia are; Complications such as a decrease in functional residual capacity in the lungs, and infections such as infection are less likely to develop after general anesthesia. Decreased blood loss in the intra operative period; in the post operative period.

\section{Case report}

Preferred reasons are decreased nausea-vomiting frequency and analgesic requirement, decreased vein thrombus and pulmonary embolism necessary permission obtained from legal representat. Spinal anesthesia was applied to patients 50 females, who underwent spinal surgery (spinal stenosis, and laminectomy) between November 2012 and September 2013 at the State Hospital. The age distribution of the patients was the smallest 23 and the largest 77.33 of the patients. $12.5 \mathrm{mg}$ heavy marcain $(0.5 \%$ bupivacaine hydrochlorure $)$ and $25 \mathrm{mcg}$ fentanyl citrate were administered intrathecally to the patients with a $25 \mathrm{G}$ pencil point spinal needle. Patients were given $1 \mathrm{mg}$ midazolam for sedation operation times were 30-180 minutes. Hypotension was observed in only 5 patients during the operation, ( $20 \%$ decrease in basal blood pressure was accepted as hypotension). Hypotension responded to ephedrine applications. Through out the operation, the block level did not rise above T8 in anypatient. No additional analgesic was required. No complications were observed operation times were 30-180 minutes. Hypotension was observed in only 5 patients during the operation, $(20 \%$ decrease in basal blood pressure was accepted as hypotension). Hypotension responded to ephedrine applications. Through out the operation, the block level did not rise above T8 in anypatient. No additional analgesic was required. No complications were observed.

\section{Discussion}

There are fewer peri operative complications such as nausea and deep vein thrombosis with spinal anesthesia. Neurological complications have not been determined after spinal anesthesia, head ache due to dura material puncture has been observed rarely and it has been stated that spinal anesthesia is an effectiveand safe alternative method to general anesthesia ${ }^{1}$ Smrcka et al., ${ }^{3}$ argued that when lumbar disc surgery cases are performed under epidural anesthesia, the surgeon's dialogue with the patient facilitates decompression. At the end of the post operative 3rd year, no negative response was obtained from patients who were asked about the degree of complaint or dissatisfaction with the operation. Study of McLain et al., ${ }^{4}$ containing 400 patients who underwent lumbar laminectomy. In various clinical studies, including high anesthesia, blood pressure and heart rate were observed to be high in the screening unit. In those who underwent spinal anesthesia :It was reported that total anesthesia time was shorter with surgery, post operative pains cores and analgesic requirement were lower, and that nausea-vomiting, urinary retention and pulmonary complications developed less. ${ }^{1,2,7}$

In lumbar disc surgery patients, it is observed that spinal anesthesia provides hemodynamic stabilization by protecting peri operative blood pressure and heart rate equivalent or better than general anesthesia. ${ }^{2}$ The change in position performed immediately after induction in general anesthesia can cause hypotension due to impaired postural sympathetic reflexes and affects negatively. ${ }^{8,9}$ While the level of spinal anesthesia is below the T8 dermatome, hemodynamics is better preserved than general anesthesia in patients brought from the supine position to the prone position, since the compensation mechanisms of the autonomic nervous system are better protected. ${ }^{6}$ It has been reported that there is less blood loss in lumbar spinal surgery, limb orthopedic and vascular system surgeries performed under regional anesthesia compared to general anesthesia. ${ }^{5}$ Peripheral venous pressure falling during lumbare pidural anesthesia in areas under anesthesia. It decreases blood pressure due to artery, arteriole vein dilatation. In addition, it reduces arterial and venous leakage to the surgical field, and due to the preservation of spontaneous ventilation in the prone position, venous leakage is prevented by decreasing the distention of epidural veins so that the surgical field it is claimed that the view is easier. Post operative tremor, which can be seen after general anesthesia, can increase pain, coronary; It may disrupt the general conditionby causing more oxygen requirement in arterial patients. ${ }^{10}$. 
When putting on regional anesthesia indication, the duration of the operation and the psychological status of the patient should be taken into consideration. Less observation of positional complications can be considered as the biggest advantage of regional anesthesia in these operations. An unconscious operation of someone who is not accustomed to the operating room can create a psychological trauma. A mild sedation can reduce this trauma. Regional anesthesia can be used effectively and safely in posterior and posterolateral spinal surgery types, single or double level laminectomies under regional anesthesia. In spinal or epidural anesthesia in vertebral surgery, the advantage of regional anesthesia for general anesthesia is to prevent complications such as brachial plexus injury, peripheral nerve injury, pressure necrosis in the face and jaw, by placing the desired position on the elbow, arm and jaw. Also, with a small amount of medication, it is virtually devoid of systemic pharmacological effects. It is suggested that surgical anesthesia can be provided as an advantage of spinal anesthesia. ${ }^{11}$ As a result; Although the advantages of spinal anesthesia are that bleeding at the time of the operation and reducing the duration of the operation room, providing more effective post operative analgesia; We believe that spinal anesthesia can be safely performed in lumbar discectomy and/or laminectomy operations.

\section{Acknowledgments}

None.

\section{Conflicts of interest}

The author declare that is no conflicts of interest.

\section{Funding}

None.

\section{References}

1. Tetzlaff JE, Dilger JA, Kodsy M, et al. Spinal anesthesia for elective lumbar spine surgery. J Clin Anesth. 1998;10(8):666-669.

2. Jellish WS, Thalji Z, Stevenson K, et al. A prospective randomized study comparing short- and intermediate-term perioperative outcome variables after spinal or general anesthesia for lumbar disk and laminectomy surgery. Anesth Analg. 1996;83(3):559-564.

3. Smrcka M, Baudysova O, Juran V, et al. Lumbar disc surgery in regional anaesthesia-40 years of experience. Acta Neurochir (Wien). 2001; 143(4):377-381.

4. McLain RF, Kalfas I, Bell GR, et al. Comparison of spinal and general anesthesia in lumbar laminectomy surgery: a case controlled analysis of 400 patients. J Neurosurg Spine. 2005;2(1):17-22.

5. Matheson D. Epidural anaesthesia for lumbar laminectomy and spinal fusion. Can Anaes Soc J. 1960;7:149-157.

6. Tetzlaff JE, O'Hara JF, Yoon HJ, et al. Heart rate variability and the prone position under general versus spinal anesthesia. J Clin Anesth. 1998;10:656-659.

7. Scott NB, Kehlet H. Regional anaesthesia and surgical morbidity. $B r J$ Surg. 1988;75(4):299-304.

8. Rodgers A, Walker N, Schug S, et al. Reduction of postoperative mortality and morbidity with epidural or spinal anaesthesia: results from overview of randomised trials. BMJ . 2000;321(7275):1493.

9. Kayhan Z. Clinical Anesthesia. Extended 3rd edition. Istanbul: Logos Publishing. 2004.

10. Frank SM, Beattie C, Christopherson R, et al. Unintentional hypothermia is associated with postoperative myocardial ischemia. the perioperative ischemia randomized anesthesia trial study group. Anesthesiology. 1993;78:468-476.

11. Brown DL. Regional Anesthesia Atlas. Third edition, Ankara: Güneș Medical Bookstores. 2008. 